\author{
J. J. Meier • A. Bhushan $\cdot$ A. E. Butler $\cdot$ R. A. Rizza • \\ P. C. Butler
}

\title{
Sustained beta cell apoptosis in patients with long-standing type 1 diabetes: indirect evidence for islet regeneration?
}

Received: 15 February 2005 / Accepted: 3 June 2005 / Published online: 5 October 2005

(C) Springer-Verlag 2005

\begin{abstract}
Aims/hypothesis: Type 1 diabetes is widely held to result from an irreversible loss of insulin-secreting beta cells. However, insulin secretion is detectable in some people with long-standing type 1 diabetes, indicating either a small population of surviving beta cells or continued renewal of beta cells subject to ongoing autoimmune destruction. The aim of the present study was to evaluate these possibilities. Materials and methods: Pancreatic sections from 42 individuals with type 1 diabetes and 14 non-diabetic individuals were evaluated for the presence of beta cells, beta cell apoptosis and replication, T lymphocytes and macrophages. The presence and extent of periductal fibrosis was also quantified. Results: Beta cells were identified in $88 \%$ of individuals with type 1 diabetes. The number of beta cells was unrelated to duration of disease (range 4-67 years) or age at death (range 14-77 years), but was higher $(p<0.05)$ in individuals with lower mean blood glucose. Beta cell apoptosis was twice as frequent in type 1 diabetes as in control subjects $(p<0.001)$, but beta cell replication was rare in both groups. The increased beta cell apoptosis in type 1 diabetes was accompanied by both increased macrophages and $\mathrm{T}$ lymphocytes and a marked increase in periductal fibrosis $(p<0.001)$, implying chronic inflammation over many years, consistent with an ongoing supply of beta cells. Conclusions/interpretation: Most people with long-standing type 1 diabetes have beta cells that continue to be destroyed. The mechanisms underlying increased beta cell death may involve both ongoing autoimmunity and glucose toxicity. The presence of beta cells despite ongoing ap-
\end{abstract}

\author{
J. J. Meier · A. Bhushan · A. E. Butler · P. C. Butler $(\bowtie)$ \\ Larry Hillblom Islet Research Center, \\ UCLA David Geffen School of Medicine, \\ 24-130 Warren Hall, 900 Veteran Avenue, \\ Los Angeles, CA 90095-7073, USA \\ e-mail: pbutler@mednet.ucla.edu \\ Tel.: +1-310-2067312 \\ Fax: +1-310-2065368 \\ R. A. Rizza \\ Division of Endocrinology, Diabetes, \\ Metabolism and Nutrition, Mayo Clinic, \\ Rochester, MN, USA
}

optosis implies, by definition, that concomitant new beta cell formation must be occurring, even after long-standing type 1 diabetes. We conclude that type 1 diabetes may be reversed by targeted inhibition of beta cell destruction.

Keywords Autoimmunity · Beta cell apoptosis · Insulin secretion - Islet regeneration - Type 1 diabetes

Abbreviations AMCA: [6-((7-amino-4-methylcoumarin3-acetyl)amino)hexanoic acid] - DAPI: 4',6-diamidino-2phenylindole - FITC: fluorescein-5-isothiocyanate .

TUNEL: terminal deoxynucleotidyl transferase biotin-dUTP nick end-labelling

\section{Introduction}

Type 1 diabetes is caused by marked insulin deficiency as a result of loss of beta cells [1-8]. While delivery of exogenous insulin therapy has greatly improved over the last 20 years, the imperfections of blood glucose control and the impact of insulin dependence on quality of life have focused attention on methods of reinstating an effective beta cell mass in people with type 1 diabetes, including islet transplantation and stem cell therapy $[9,10]$. An alternative approach is the possibility of endogenous beta cell regeneration [11].

The mechanism of beta cell loss in type 1 diabetes is presumed to be beta cell destruction mediated by autoimmunity [12]. Based on animal studies, it is assumed that decreased beta cell mass in type 1 diabetes is due to increased beta cell apoptosis $[13,14]$. It has been reported that some patients with long-standing type 1 diabetes have occasional beta cells scattered in the pancreas $[3,8]$. Theoretically, these cells may be long-standing survivors or may represent newly formed beta cells that are, presumably, subject to ongoing autoimmune-mediated destruction. If the latter were true, this would indicate some regenerative capacity for beta cell renewal in type 1 diabetes that could be harnessed by selective inhibition of the autoimmune process to restore endogenous insulin secretion. 
In order to address this, we examined pancreas samples obtained at autopsy in 42 patients with type 1 diabetes to establish the extent to which beta cells are present in patients with long-standing type 1 diabetes and, if present, whether these cells show evidence of ongoing destruction, which would imply a concomitant source of new beta cell formation.

\section{Subjects and methods}

Subjects Human pancreatic tissue was obtained at autopsy from 42 individuals with type 1 diabetes $(24$ male, 18 female; age $40.5 \pm 12.5$ years; BMI $22.2 \pm 5.1 \mathrm{~kg} / \mathrm{m}^{2}$; glucose $14.7 \pm 5.8 \mathrm{mmol} / \mathrm{l})$. Potential cases were identified by retrospective analysis of the Mayo Clinic autopsy database. To be included, cases were required to have had: (1) a full autopsy within $12 \mathrm{~h}$ of death; (2) a general medical examination, including at least one blood glucose measurement documented within the year before death; and (3) pancreatic tissue stored that was of adequate size and quality. Subjects were excluded if pancreatic tissue had undergone autolysis or showed evidence of acute pancreatitis.

The diagnosis of type 1 diabetes was established clinically by independent chart review by three physicians (P. C. Butler, R. A. Rizza and J. J. Meier) according to the following criteria: (1) ketosis at diabetes onset; (2) young age of onset (most were aged 10-18 years); (3) absence of a family history of type 2 diabetes; and (4) immediate insulin requirement after diabetes onset, with sustained requirement. Clinical diagnosis was supported by pathological evaluation of pancreas (marked beta cell deficit, absence of islet amyloid and absence of pancreatitis). Eleven of the 42 cases of type 1 diabetes had received a renal transplant and subsequent immunosuppressive therapy. Pancreatic specimens from six non-diabetic subjects (three male, three female; age $49.8 \pm 15.3$ years, BMI $27.7 \pm 6.5 \mathrm{~kg} / \mathrm{m}^{2}$, glucose $5.1 \pm 0.94 \mathrm{mmol} / \mathrm{l})$ were obtained from tumour-free pancreas removed at surgery for adenocarcinoma of the biliary tree or pancreatic adenomas, and from eight non-diabetic subjects (four male, four female; age $37 \pm 10$ years; BMI $20.2 \pm$ $3.0 \mathrm{~kg} / \mathrm{m}^{2}$, glucose $5.1 \pm 0.3 \mathrm{mmol} / \mathrm{l}$ ) at the time of autopsy. None of the latter group of eight non-diabetic subjects was known to have any disease affecting the pancreas prior to death.

Neither glycosylated haemoglobin nor home blood glucose monitoring values were available for the diabetic subjects, as these were not commonly used at the time of death of these individuals. Therefore, to obtain the best possible estimate of glycaemic control, all laboratorymeasured blood glucose concentrations documented in the medical record (average recorded values $8.3 \pm 0.6$, range 2 $23 \mathrm{mmol} / \mathrm{l}$ ) were used to calculate a mean glucose value, which was then compared with beta cell abundance.

The number of pancreatic tissue blocks available per diabetic subject was as follows: one block in 27 cases, two blocks in ten cases, three blocks in one case, four blocks in one case and six blocks in three cases. Of the three diabetic subjects in which no beta cells could be detected, two had one block and one had two blocks. Of the four patients with the most insulin-positive islets, three had one block and one had four blocks. In this latter case, one block revealed multiple islets with insulin-positive cells and numerous scattered individual beta cells; one block had one islet with insulin-positive cells, but no individual scattered beta cells; the third and fourth blocks had numerous individual scattered beta cells, but the islets contained no insulin-positive cells.

Pancreatic tissue processing Pancreas was fixed in formaldehyde and embedded in paraffin for subsequent analysis as previously described [15]. Five sequential $5-\mu \mathrm{m}$ sections were stained as follows: (1) for insulin (peroxidase staining) and haematoxylin for light microscopy; (2) insulin and cleaved caspase-3 combined (immunofluorescence); (3) insulin, terminal deoxynucleotidyl transferase biotin-dUTP nick end-labelling (TUNEL) and 4',6-diamidino-2-phenylindole (DAPI; immunofluorescence); (4) insulin, Ki67 and DAPI combined (immunofluorescence); and (5) insulin, CD3 and CD68 combined (immunofluorescence).

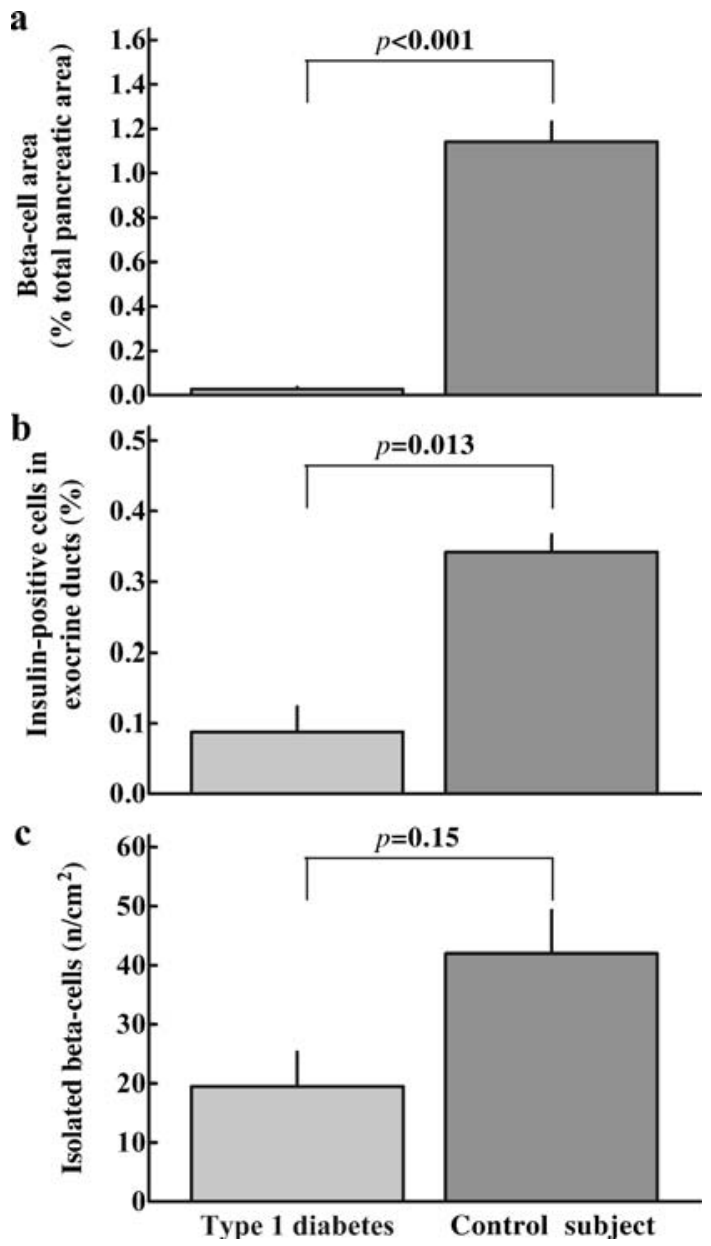

Fig. 1 a The fractional beta cell area positive for insulin in type 1 diabetic patients vs non-diabetic control subjects. b Percentage of exocrine duct cells positive for insulin in type 1 diabetic patients and control subjects. c Abundance of scattered insulin-positive cells in pancreatic acinar tissue in type 1 diabetic patients and non-diabetic controls. The data are shown as means \pm SEM (ANOVA) 
The following primary antibodies were used for immunofluorescence: guinea-pig anti-insulin, 1:200 (Dako, Grostrup, Denmark); mouse Ki67, 1:200 (MIB-1, Dako); rabbit cleaved caspase-3, 1:50 (Biocare Medical, Concord, CA, USA); rabbit CD3, 1:50 (Dako); mouse CD68, 1:100 (Dako). Secondary antibodies labelled with Cy3, fluorescein-5-isothiocyanate (FITC) and [6-((7-amino-4-methylcoumarin-3-acetyl)amino)hexanoic acid] (AMCA) were obtained from Jackson Laboratories (West Grove, PA, USA) and used at dilutions of 1:100 to 1:200. For TUNEL staining, the in situ cell death detection kit TMR Red from Roche Diagnostics (Mannheim, Germany) was used.

Morphometrical analysis The ratio of the beta cell area: exocrine area was quantified as previously described [15]. The frequency of scattered single beta cells unrelated to islets or pancreatic ducts was counted manually in each subject and expressed relative to pancreas area. The frequency of insulin-positive cells in exocrine ducts $(\sim 60$ ducts per subject) was determined manually.

Beta cell apoptosis and replication Beta cell apoptosis in type 1 diabetic patients and non-diabetic control subjects was identified using TUNEL staining as previously described [15]. Since TUNEL detects DNA-strand breaks, it is theoretically possible that the frequency of TUNEL- positive cells in a pancreatic specimen obtained at autopsy is artefactually increased due to post-mortem changes. Therefore, cleaved caspase-3, which represents the final activation step in the apoptotic signalling cascade, was used as an additional marker for beta cell apoptosis. Moreover, the frequency of cleaved caspase-3-positive beta cells was compared between non-diabetic individuals with a pancreatic specimen obtained at autopsy $(n=8)$ and those with a specimen obtained at surgery $(n=6)$. The frequency of beta cell apoptosis by cleaved caspase-3 was similar in these tissue samples ( $2.8 \pm 0.2$ vs $1.9 \pm 0.4 \%$, NS). To compute a meaningful relative frequency of either beta cell replication or apoptosis in type 1 diabetic patients vs non-diabetic control subjects, sufficient beta cells per subject are required. There were insufficient beta cells in most subjects with type 1 diabetes to allow this computation. We therefore used the values for the four type 1 diabetic patients with the greatest number of detectable beta cells and compared these with the values for the eight non-diabetic control subjects. In these 12 subjects, slides were co-stained for insulin (FITC) and cleaved caspase-3 (Cy3). Ten islets from each of these 12 cases were examined in detail at $\times 200$ magnification $(\times 20$ objective, $\times 10$ ocular). The number of beta cells was counted and the number of beta cells positive for caspase- 3 in these ten islets documented. A total of 2,690 and 6,679 beta cells
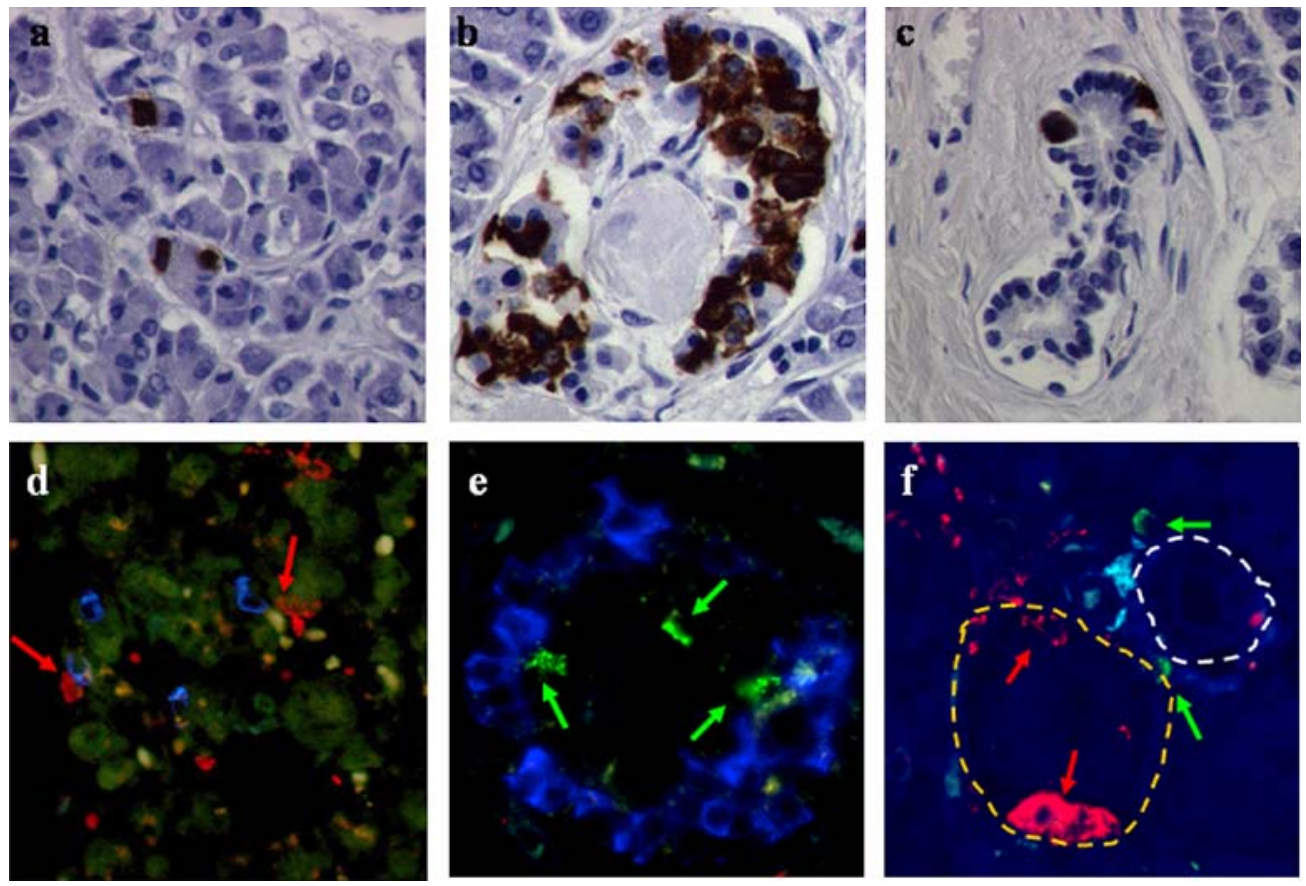

Fig. 2 a Scattered beta cells (insulin staining) in pancreatic acinar tissue in a type 1 diabetic patient (age 39 years, diabetes duration 30 years). b Beta cells in an islet of a type 1 diabetic patient (age 42 years, diabetes duration 23 years). The islet is atrophic with a central hyaline degenerative core. The beta cells are irregularly shaped and the usually orderly cell-to-cell relations within the islets are disrupted. c Two insulin-positive cells in an exocrine duct from a patient with long-standing type 1 diabetes (age 42 years, diabetes duration 23 years). There is abundant fibrosis around the duct, which is a common feature of type 1 diabetes. d Macrophages (red) in close proximity to scattered beta cells (blue) in acinar tissue of a case of type 1 diabetes (age 60 years, diabetes duration 57 years). e T lymphocytes (green) in an islet with beta cells (blue) of a patient with long-standing type 1 diabetes (age 42 years, diabetes duration 23 years). f An exocrine duct (white circle) in close proximity to an islet that contains no insulin-positive cells (yellow circle) in a patient with type 1 diabetes (age 60 years, diabetes duration 57 years). There are two $\mathrm{T}$ lymphocytes (green) in directly adjacent to the duct cells. Macrophages $(\mathrm{red})$ surround and infiltrate the islet. The macrophages in the islet (lower arrow) appear enlarged, consistent with recent phagocytosis. Images were taken at $\times 200$ magnification 
were evaluated thus in the four type 1 diabetic patients and the eight autopsy control subjects, respectively. Slides from the same subjects co-stained for insulin (FITC), Ki67 (Cy3) and DAPI were evaluated for the frequency of beta cell replication, using a method similar to that used to assess apoptosis.

As the frequency of replication in human islets is extremely low (in comparison with murine islets), we performed several positive controls to ensure that Ki67 is a valid marker for replication in the paraffin-embedded tissue obtained at autopsy, and that this well-documented marker for cell replication provides a reliable measure of beta cell replication in humans. Therefore, samples of human tissue (spleen, pancreas, liver [autopsy] and pancreatic insulinoma [surgery]), fixed and processed under identical conditions in the same pathology laboratory (Mayo Clinic), were similarly stained for Ki67. Ki67-positive cells were observed to be scattered similarly in exocrine tissue from both type 1 diabetic patients and control subjects. As expected, splenic white pulp was characterised by a high frequency of Ki67-positive cells, clearly indicating cell division. Ki67-positive cells were also present in liver. In addition, Ki67-positive dividing beta cells were evident in a human insulinoma.

To quantify the extent of fibrosis, haematoxylin- and insulin-stained slides from each subject were evaluated by light microscopy. Each subject was scored using an arbitrary scale of 0 to 4 , where 0 indicates no fibrosis present; 1 , minimal fibrosis in the periductal area; 2 , moderate fibrosis in the periductal area; 3 , marked fibrosis around ducts and in the interlobular area; and 4, severe extensive fibrosis around ducts and in the interlobular area.

Statistical analysis Subject characteristics are reported as means \pm SD and results are presented as means \pm SEM. Statistical calculations were carried out by one-way ANOVA and Duncan's post hoc test using Statistica, Version 6.0 (Statsoft, Tulsa, OK, USA). Categorical variables were analysed by Fisher's exact test using GraphPad Prism 4 (San Diego, CA, USA). A $p$ value of less than 0.05 was considered statistically significant.

\section{Results}

Number and distribution of beta cells in type 1 diabetes As anticipated, there was a striking beta cell deficit in type 1 diabetic patients vs non-diabetic control subjects $(0.027 \pm$ 0.010 vs $1.140 \pm 0.090 \%, p<0.0001$ ) (Fig. 1). However, insulin-positive cells were identified in $88 \%$ of patients with type 1 diabetes. Beta cells in non-diabetic control subjects were distributed in three distinct patterns: (1) within islets; (2) in clusters of cells within and attached to exocrine ducts; and (3) as single beta cells scattered within the pancreas acinar tissue. With respect to the 42 type 1 diabetic patients, in the samples of pancreas available, five had no detected insulin-positive cells; 16 had insulin-positive cells in islets, with four of these individuals showing multiple insulin-positive islets; 15 had insulin-positive cells in clusters or individually within exocrine ducts; and 37 had insulin-positive cells scattered in the pancreatic acinar tissue (Fig. 2). The number of beta cells in the type 1 diabetic patients was significantly lower within the islets $(p<0.001)$, within exocrine ducts $(p=0.013)$, and by trend in the exocrine parenchyma $(p=0.15$; Fig. 1$)$ than in the non-diabetic control subjects. When beta cells were present within the islets of type 1 diabetic patients, they were typically adjacent to areas of hyaline-degenerative material containing nuclear fragments. Moreover, the beta cells often exhibited degenerative changes such as condensed
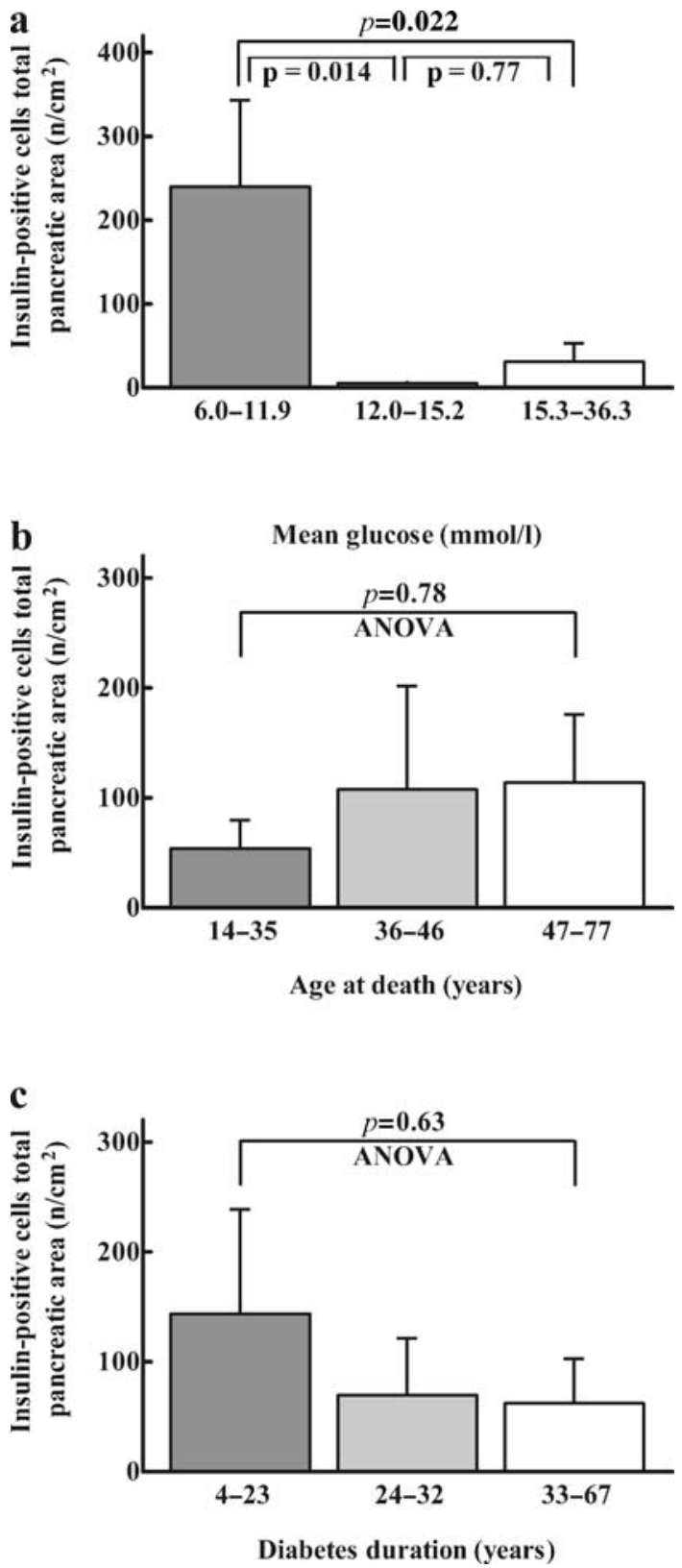

Fig. 3 Abundance of beta cells per pancreatic area in 37 patients with type 1 diabetes with detectable beta cells, examined in relation to tertiles of mean blood glucose (a), age at death (b) and diabetes duration (c). Data are presented as means \pm SEM (ANOVA and Duncan's post hoc analysis) 
Fig. 4 Examples of islets in a patient with type 1 diabetes (a) and a non-diabetic autopsy control subject (c) stained for insulin (green) and cleaved caspase-3 (for apoptosis; red) and imaged at $\times 200$ magnification. Panels $\mathbf{b}$ and $\mathbf{d}$ show inserts taken from these images at higher magnification. Arrows indicate apoptosis in beta cells (green). Right panels indicate the frequency of apoptosis in beta cells (e), determined in four patients with type 1 diabetes and eight non-diabetic autopsy control subjects. Data are presented as means \pm SEM (one-way ANOVA)

\section{Type 1 diabetes}
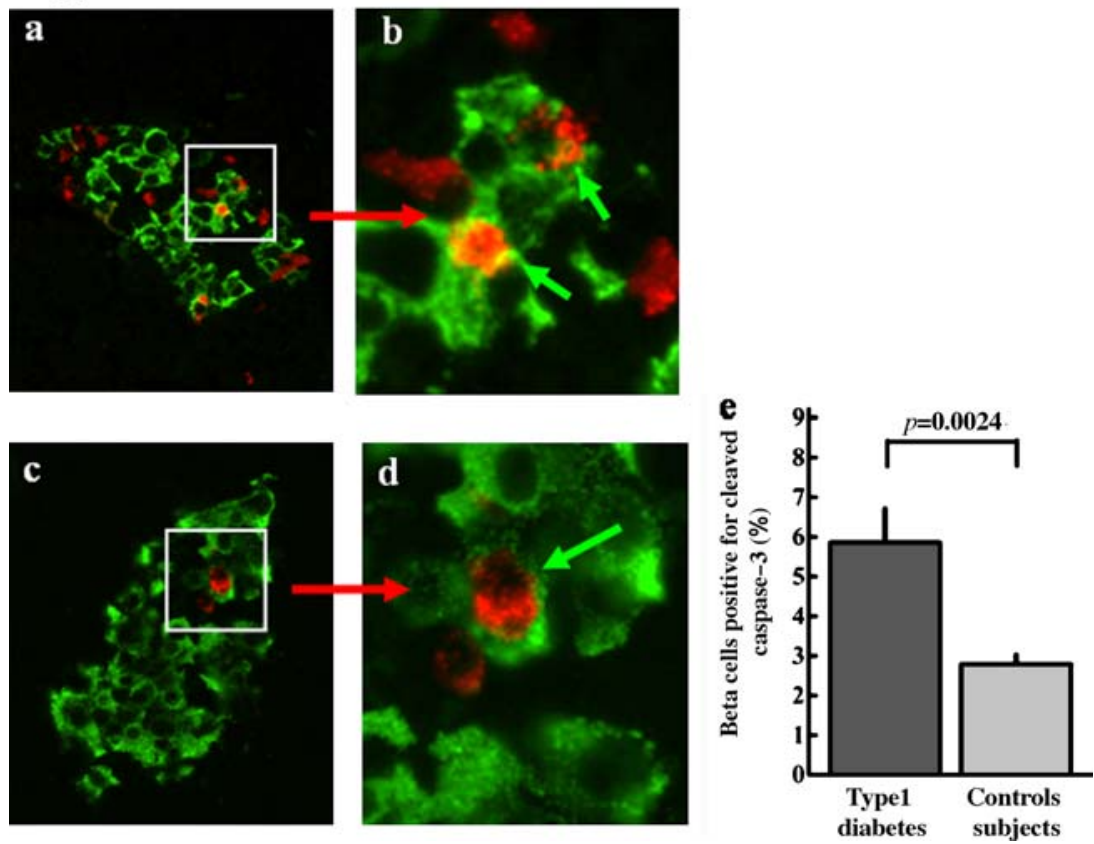

nuclei, hydropic cytoplasm and loss of typical cell-to-cell organisation.

Relationship between beta cell number and clinical characteristics To explore the relationship between blood glucose control and beta cell number in type 1 diabetes, the diabetic subjects were divided into tertiles according to mean blood glucose concentrations. The results suggest a possible threshold mean blood glucose at $\sim 11 \mathrm{mmol} / \mathrm{l}$, below which there are more beta cells. In contrast, the number of beta cells was independent of diabetes duration and age at death (Fig. 3). There was also no relationship between the fractional pancreatic beta cell number and insulin dosage, BMI or age at diabetes onset (data not shown). Eleven individuals with type 1 diabetes had received immunosuppressive therapy for renal transplantation prior to death (average duration of treatment $8.3 \pm 5.5$ months). The frequency of beta cells in previously im-
Fig. 5 Examples of beta cell apoptosis in an islet (a) and in a single beta cell scattered in the acinar tissue (b) in a patient with type 1 diabetes. In non-diabetic control subjects, TUNEL-positive cells were rarely present in islets (c), but were occasionally found in the acinar tissue (d). Slides were stained for insulin (green), TUNEL (for apoptosis; red) and DAPI (for nuclei; blue), and images were taken at $\times 200$ magnification. Arrows indicate beta cell apoptosis
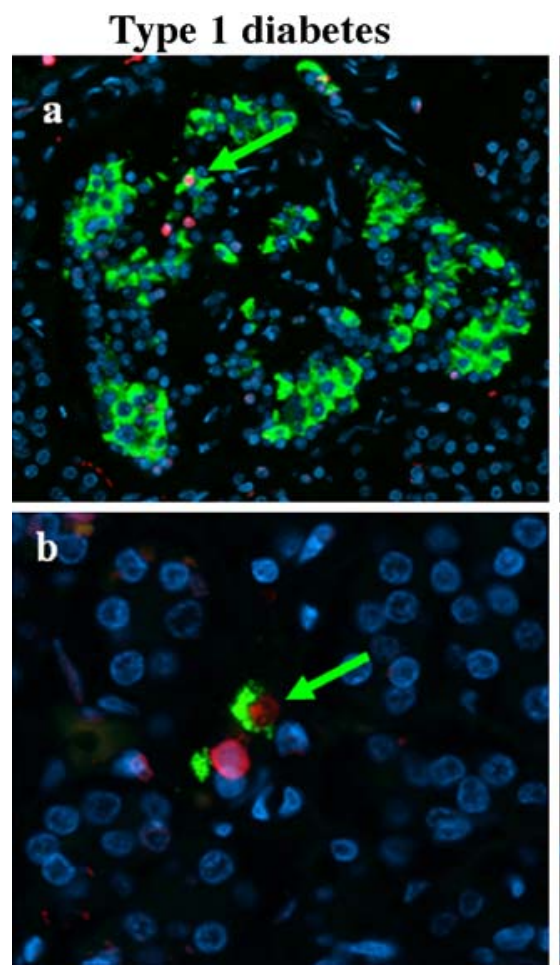

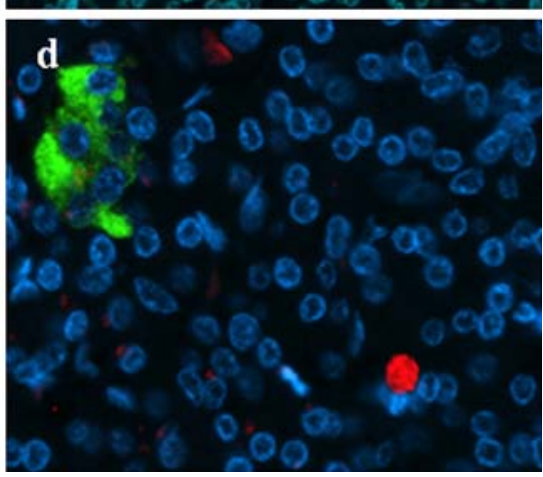


munosuppressed patients was lower, although not significantly, than in the other patients with type 1 diabetes (5.3 \pm 2.2 vs $104.8 \pm 43.8$ cells $/ \mathrm{cm}^{2}, p=0.19$ ).

Beta cell apoptosis and replication Beta cell apoptosis, assessed using either TUNEL or cleaved caspase-3 as markers, was higher in patients with type 1 diabetes than in non-diabetic autopsy control subjects (Figs. 4 and 5). The frequency of beta cell apoptosis (cleaved caspase-3) was approximately two-fold higher in the four type 1 diabetic patients with sufficient beta cells in islets to allow quantification than in the non-diabetic autopsy control subjects $(p<0.01$; Fig. 4). Beta cell apoptosis was detected both in beta cells within islets as well as in scattered single beta cells (Fig. 5).

Consistent with previous human studies [15], the frequency of replication, assessed by staining with $\mathrm{Ki}-67$, was extremely low in beta cells. In total, three Ki67-positive cells co-stained for insulin were found in a total of 80 islets examined in the autopsy control cases, while no Ki67positive cells were detected in a total of 40 islets examined in patients with type 1 diabetes. In contrast, replication was frequently detected in the acinar tissue and exocrine ducts (Fig. 6).

Macrophages, $T$ cells and pancreatic fibrosis CD3-positive $\mathrm{T}$ cells were readily identified in islets of both type 1

\section{Type 1 diabetes}
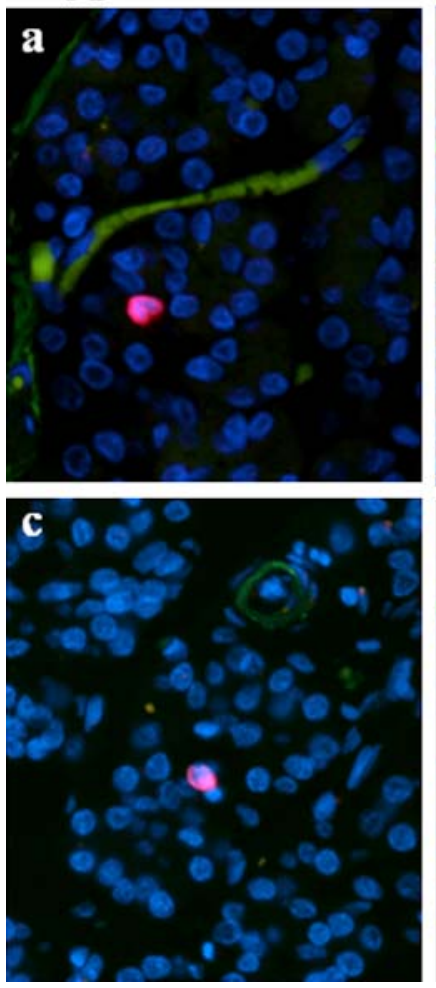

\section{Control subjects}
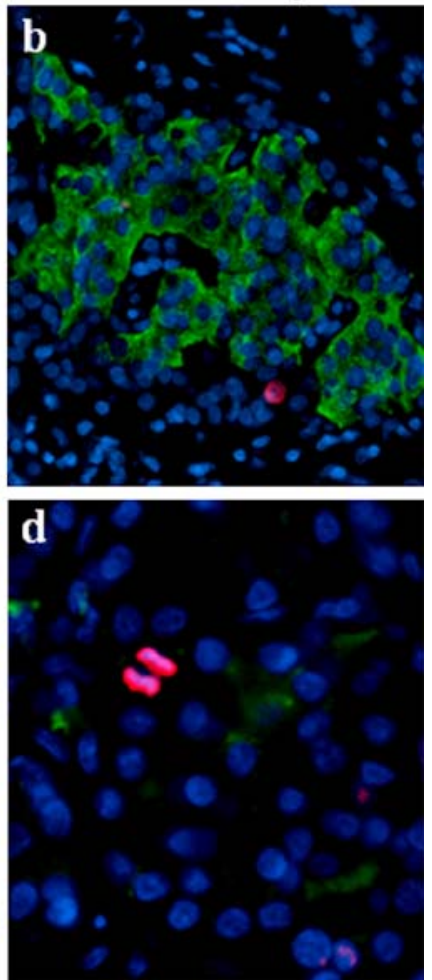

Fig. 6 Examples of pancreas stained for replication by Ki67 (red), insulin (green), nuclei (blue) in patients with type 1 diabetes (a, c) and in non-diabetic control subjects $(\mathbf{b}, \mathbf{d})$ imaged at $\times 200$ magnification. While replication was commonly present in acinar tissue and exocrine ducts, it was very rarely present in beta cells diabetic patients and control subjects, whereas they were infrequently seen in the exocrine parenchyma (Fig. 2). The extent of the $\mathrm{T}$ cell infiltrate in the patients with longstanding diabetes never approached the extent that is often termed insulitis in the islets of new-onset type 1 diabetes, but was approximately 1.5 -fold higher in patients with type 1 diabetes than in control subjects. As expected, macrophages could be identified scattered in both exocrine and endocrine tissue, but were more abundant in islets of patients with type 1 diabetes ( two-fold) than in those of control subjects. Macrophages were also present adjacent to scattered beta cells in pancreatic acinar tissue in type 1 diabetes. $T$ cells and macrophages were more commonly present in close proximity to exocrine ducts, which had adjacent islets, in type 1 diabetic patients than in control subjects.

As previously reported, we frequently observed pancreatic fibrosis in patients with type 1 diabetes. In its mildest form, this fibrosis was periductal only, but when more extensive, extended to the interlobular areas. All type 1 diabetic patients had fibrosis, $40 \%$ had periductal fibrosis (grade 1 or 2 ) only, and $60 \%$ of cases had periductal fibrosis extending to interlobular pancreas. In contrast, only one of the control subjects had any pancreatic fibrosis detected, which was also periductal, but was less extensive than in any of the diabetic patients.

\section{Discussion}

In the present study we report that beta cells are present in the majority of people with type 1 diabetes, and that the number of these cells is not related to duration of diabetes. The high frequency of apoptosis in beta cells in longstanding type 1 diabetes implies ongoing beta cell provision in these people.

Several prior studies have reported scattered single beta cells or beta cells within islets from pancreas samples obtained at autopsy or surgical biopsy in patients with type 1 diabetes $[3,5-7,16]$. Here we show the presence of a greater number of beta cells in individuals with better glycaemic control, an observation consistent with some studies of insulin secretion in type 1 diabetes [17-22]. This relationship may a indicate benefit of glycaemic control from residual beta cells and/or decreased rates of beta cell apoptosis secondary to glucose toxicity [23, 24]. However, since the nature of this study did not allow systematic assessment of glucose values, these data should be interpreted with some caution.

In the present study we report that insulin-positive beta cells are still present at 67 years after the onset of diabetes, and that the duration of the disease, the age at onset of diabetes and age at death are not predictors of the extent of the beta cells. The presence of beta cells despite longstanding type 1 diabetes implies either a sustained supply of beta cells or a subpopulation of beta cells resistant to cell death. It is important to note that, in the present study, only one tissue block was analysed in the majority of the patients with type 1 diabetes. Given the unequal distribu- 
tion of beta cells within the pancreas, it is likely that the true percentage of type 1 diabetic patients with beta cells in the pancreas is even higher than the $88 \%$ reported here.

It has been suggested that a critical mass of cells expressing relevant antigens must be present to sustain autoimmune destruction, raising the possibility that the rate of immune-mediated beta cell destruction declines after the number of beta cells decreases to a critical threshold [25]. However, human beta cells are also vulnerable to apoptosis when exposed to glucose concentrations of approximately $11 \mathrm{mmol} / \mathrm{l}(200 \mathrm{mg} / \mathrm{dl})$ or higher through mechanisms that include beta cell expression and the action of IL-1 [24]. As the mean blood glucose concentration in the majority of cases included in this report exceeded $11 \mathrm{mmol} / \mathrm{l}$, it would seem unlikely that the presence of beta cells in longstanding diabetes can be ascribed solely to a residual pool of surviving beta cells. Indeed, if beta cells are still present despite a sustained increased rate of beta cell apoptosis in people with long-standing type 1 diabetes, then, by definition, concomitant new beta cell formation must be occurring.

In order to explore this possibility, we compared the frequency of beta cell apoptosis in patients with type 1 diabetes with that in non-diabetic control subjects. One of the limitations associated with studies of human pancreas from type 1 diabetic patients to evaluate beta cell apoptosis is the very low abundance of beta cells. We attempted to address this in the present study by examining the frequency of beta cell apoptosis in the four cases with the most beta cells. The frequency of beta cell apoptosis in these four patients was approximately two-fold greater than that in the non-diabetic subjects. It is possible that these patients are not representative of the type 1 diabetic population. To investigate this, we examined the clinical characteristics of these four patients in detail and compared them with those of the other 38 cases. There was no difference in age of onset ( $15 \pm 2$ vs $11 \pm 1$ years), insulin dose $\left(0.8 \pm 0.1\right.$ vs $0.7 \pm 0.1 \mathrm{U} \mathrm{kg}^{-1}$ day $\left.^{-1}\right)$, mean blood glucose $12.8 \pm 2.8$ vs $14.3 \pm 0.9 \mathrm{mmol} / \mathrm{l})$ or age at death $(31 \pm 7$ vs $42 \pm$ 2 years). None of the four patients with the highest number of beta cells had received renal transplants or immunosuppression. It might be argued that the four patients with the most abundant beta cells had a milder form of autoimmune disease. However, since the frequency of beta cell apoptosis was increased in these cases compared with that in control subjects, then one might predict that this frequency may be even higher in diabetic patients with much fewer beta cells. Indeed, the frequency of apoptosis seemed to be increased in scattered single beta cells of patients with type 1 diabetes (Fig. 5), even though the limited number of these cells did not allow formal quantification.

The increased frequency of beta cell apoptosis in type 1 diabetes argues against the hypothesis that the beta cells present in the pancreas of people with long-standing type 1 diabetes are residual beta cells resistant to destruction. By inference, these findings support the alternative postulate, that the beta cells present in type 1 diabetes are evidence of sustained beta cell provision, which appears to be independent of duration of diabetes or age of onset of diabetes
If so, then what is the source of this sustained beta cell provision?

A number of potential sources have been proposed. These have been recently reviewed in an elegant study by Dor and colleagues, who convincingly demonstrated that expansion of beta cell number in adult mice is accomplished through replication of existing beta cells, and that any provision of puripotential stem cells is negligible [26]. However, in contrast to mice, where beta cell replication appears to be an important mechanisms for beta cell expansion even during adult life $[27,28]$, we were unable to demonstrate high rates of replication of existing beta cells in the pancreases of diabetic or non-diabetic human subjects (Fig. 6), consistent with prior reports of studies on human pancreas $[3,15,29]$. It is possible that the beta cells were committed to replication in type 1 diabetes but, given the increased vulnerability of replicating beta cells to apoptosis, underwent apoptosis instead [30]. Transdifferentiation of acinar cells is another proposed explanation [31]. In the present experiments we observed occasional single beta cells scattered in acinar tissue in pancreases of type 1 diabetes patients and non-diabetic control subjects. However, if this were a significant source of new beta cells, one would expect replication rates to be increased within these scattered single cells, and this was not observed. Alternatively, new islets could originate from ductal precursor cells in a manner comparable to the prenatal origin of islets [32]. Although Dor and colleagues ruled out this mechanism in mice [26], it could conceivably occur in humans.

A limitation of the present study is that we can only provide indirect evidence for islet regeneration by showing increased beta cell apoptosis in subjects with long-standing type 1 diabetes. Beta cell replication appears to be rare in adult humans and, as discussed, the origin of new beta cells in humans is controversial, complicated by the fact that lineage tracing studies are not feasible in humans. Therefore, in humans, indirect strategies, such as those used here, are required to explore beta cell regeneration.

It has previously been reported that the pancreas of people with type 1 diabetes is characterised by increased fibrosis, small size and impaired exocrine function $[3,7,8$, $33,34]$. This has led to speculation that this might be due to a separate autoimmune process affecting the exocrine pancreas [35]. Alternatively, it has been proposed that loss of the trophic effect of insulin in patients with type 1 diabetes may lead to acinar cell atrophy $[7,36]$. However, we noted in the present studies that this fibrosis predominantly surrounds exocrine ducts. Thus, it is possible that this fibrosis may be secondary to a chronic periductal inflammation arising from newly supplied beta cells subject to autoimmune-mediated destruction. This would also be consistent with the presence of macrophages and $T$ lymphocytes in islets adjacent to exocrine ducts, suggesting that the source of new beta cells is proximal to the ducts.

In summary, the present studies demonstrate that beta cells are present in the majority of people with type 1 diabetes, irrespective of the duration of diabetes or age of death. Furthermore, we report that beta cell apoptosis is 
ongoing and increased in type 1 diabetes, indicating that there is a continued source of beta cell replenishment in these people. The source of this supply remains unknown, but its existence has immediate clinical implications. If the increased frequency of beta cell apoptosis in type $1 \mathrm{di}-$ abetes could be overcome, at least some regeneration of beta cell mass and return of function might be accomplished. Of note, the possibility of beta cell regeneration in people with type 1 diabetes was proposed as early as 1925 by Warren and Root [1].

Acknowledgements These studies were supported by grants from the US Public Health Service NIH DK 59567 (P. C. Butler), DK 29953 (R. A. Rizza) and DK68763 (A. Bhushan); the Larry L. Hillblom Foundation; and the German Research foundation (Deutsche Forschungsgemeinschaft, Me 2096/2-1). We gratefully acknowledge the technical assistance of R. Soliz and P. Kasey, and the helpful suggestions of T. Gurlo and S. Georgia.

\section{References}

1. Warren S, Root HF (1925) The pathology of diabetes, with special reference to pancreatic regeneration. Am J Pathol 1: 415-430

2. Stansfield $\mathrm{OH}$, Warren S (1928) Inflammation involving the islets of Langerhans in diabetes. N Engl J Med 198:686-687

3. Gepts W (1965) Pathologic anatomy of the pancreas in juvenile diabetes mellitus. Diabetes 14:619-633

4. Junker K, Egeberg J, Kromann H, Nerup J (1977) An autopsy study of the islets of Langerhans in acute-onset juvenile diabetes mellitus. Acta Pathol Microbiol Scand A 85:699-706

5. Gepts W, De Mey J (1978) Islet cell survival determined by morphology. An immunocytochemical study of the islets of Langerhans in juvenile diabetes mellitus. Diabetes 27 (Suppl 1):251-261

6. Rahier J, Goebbels RM, Henquin JC (1983) Cellular composition of the human diabetic pancreas. Diabetologia 24:366-371

7. Lohr M, Kloppel G (1987) Residual insulin positivity and pancreatic atrophy in relation to duration of chronic type 1 (insulin-dependent) diabetes mellitus and microangiopathy. Diabetologia 30:757-762

8. Pipeleers D, Ling Z (1992) Pancreatic beta cells in insulindependent diabetes. Diabetes Metab Rev 8:209-227

9. Robertson RP (2004) Islet transplantation as a treatment for diabetes - a work in progress. N Engl J Med 350:694-705

10. Cheung AT, Dayanandan B, Lewis JT et al (2000) Glucosedependent insulin release from genetically engineered $\mathrm{K}$ cells. Science 290:1959-1962

11. Halban PA (2004) Cellular sources of new pancreatic beta cells and therapeutic implications for regenerative medicine. Nat Cell Biol 6:1021-1025

12. Atkinson MA, Eisenbarth GS (2001) Type 1 diabetes: new perspectives on disease pathogenesis and treatment. Lancet 358221-229

13. Kurrer MO, Pakala SV, Hanson HL, Katz JD (1997) Beta cell apoptosis in T cell-mediated autoimmune diabetes. Proc Natl Acad Sci U S A 94:213-218

14. Jorns A, Kubat B, Tiedge M et al (2004) Pathology of the pancreas and other organs in the diabetic LEW.1AR1/Ztm-iddm rat, a new model of spontaneous insulin-dependent diabetes mellitus. Virchows Arch 444:183-189

15. Butler AE, Janson J, Bonner-Weir S et al (2003) Beta-cell deficit and increased beta-cell apoptosis in humans with type 2 diabetes. Diabetes 52:102-110
16. Imagawa A, Hanafusa $T$, Tamura $S$ et al (2001) Pancreatic biopsy as a procedure for detecting in situ autoimmune phenomena in type 1 diabetes: close correlation between serological markers and histological evidence of cellular autoimmunity. Diabetes 50:1269-1273

17. Faber OK, Binder C (1977) B-cell function and blood glucose control in insulin dependent diabetics within the first month of insulin treatment. Diabetologia 13:263-268

18. Madsbad S, Krarup T, Reguer L, Faber OK, Binder C (1981) Effect of strict blood glucose control on residual B-cell function in insulin-dependent diabetics. Diabetologia 20:530-534

19. Madsbad S (1983) Prevalence of residual B cell function and its metabolic consequences in type 1 (insulin-dependent) diabetes. Diabetologia 24:141-147

20. The DCCT Research Group (1987) Effects of age, duration and treatment of insulin-dependent diabetes mellitus on residual beta-cell function: observations during eligibility testing for the Diabetes Control and Complications Trial (DCCT). J Clin Endocrinol Metab 65:30-36

21. The Diabetes Control and Complications Trial Research Group (1998) Effect of intensive therapy on residual beta-cell function in patients with type 1 diabetes in the diabetes control and complications trial. A randomized, controlled trial. Ann Intern Med 128:517-523

22. Kolb H, Gale EA (2001) Does partial preservation of residual beta-cell function justify immune intervention in recent onset type I diabetes? Diabetologia 44:1349-1353

23. Robertson RP, Harmon J, Tran PO, Poitout V (2004) Beta-cell glucose toxicity, lipotoxicity, and chronic oxidative stress in type 2 diabetes. Diabetes 53(Suppl 1):S119-S124

24. Maedler K, Sergeev P, Ris F et al (2002) Glucose-induced beta cell production of IL-1beta contributes to glucotoxicity in human pancreatic islets. J Clin Invest 110:851-860

25. Bach JF (1994) Insulin-dependent diabetes mellitus as an autoimmune disease. Endocr Rev 15:516-542

26. Dor Y, Brown J, Martinez OI, Melton DA (2004) Adult pancreatic beta-cells are formed by self-duplication rather than stem-cell differentiation. Nature 429:41-46

27. Wang RN, Bouwens L, Kloppel G (1996) Beta-cell growth in adolescent and adult rats treated with streptozotocin during the neonatal period. Diabetologia 39:548-557

28. Butler AE, Janson J, Soeller WC, Butler PC (2003) Increased beta-cell apoptosis prevents adaptive increase in beta-cell mass in mouse model of type 2 diabetes: evidence for role of islet amyloid formation rather than direct action of amyloid. Diabetes 52:2304-2314

29. Bouwens L, Pipeleers DG (1998) Extra-insular beta cells associated with ductules are frequent in adult human pancreas. Diabetologia 41:629-633

30. Ritzel RA, Butler PC (2003) Replication increases beta-cell vulnerability to human islet amyloid polypeptide-induced apoptosis. Diabetes 52:1701-1708

31. Lipsett M, Finegood DT (2002) Beta-cell neogenesis during prolonged hyperglycemia in rats. Diabetes 51:1834-1841

32. Edlund H (2002) Pancreatic organogenesis-developmental mechanisms and implications for therapy. Nat Rev Genet 3: 524-532

33. Vacca JB, Henke WJ, Knight WA Jr (1964) The exocrine pancreas in diabetes mellitus. Ann Intern Med 61:242-247

34. Lankisch PG, Manthey G, Otto J et al (1982) Exocrine pancreatic function in insulin-dependent diabetes mellitus. Digestion 25:211-216

35. Kobayashi T, Nakanishi K, Kajio H et al (1990) Pancreatic cytokeratin: an antigen of pancreatic exocrine cell autoantibodies in type 1 (insulin-dependent) diabetes mellitus. Diabetologia 33:363-370

36. Foulis AK, Stewart JA (1984) The pancreas in recent-onset type 1 (insulin-dependent) diabetes mellitus: insulin content of islets, insulitis and associated changes in the exocrine acinar tissue. Diabetologia 26:456-461 